\title{
Modified Bentonite with Dithizone as Nano Clay Mineral Adsorbent for Solid Phase Extraction of Silver lons
}

\author{
Farid Shakerian, ${ }^{1,2,}$ Shayessteh Dadfarnia, ${ }^{1}$ Ali Mohammad Haji Shabani, ${ }^{1}$ Mahboubeh Saeidi, ${ }^{3}$ \\ Seyed Mohammad Sadegh Hosseini ${ }^{3}$
}

\footnotetext{
1 Department of Chemistry, Faculty of Sciences, Yazd University, Yazd, Iran

2 Current address: School of Earth and Environmental Sciences, Seoul National University, Seoul 08826, Korea

3 Department of Chemistry, Faculty of Sciences, Vali-e-Asr University of Rafsanjan, Rafsanjan, Iran

* Corresponding author's e-mail address: fshakerian@snu.ac.kr
}

RECEIVED: April 5, 2016 * REVISED: August 16, 2016 * ACCEPTED: September 9, 2016

Abstract: In this work, a simple flow injection system incorporating a microcolumn of immobilized dithizone on bentonite coated with cetyltrimethylammonium bromide was combined with flame atomic absorption spectrometry (FAAS) for on-line separation/preconcentration and determination of trace amounts of silver in water. Dithizone was physically immobilized on the surfactant coated bentonite particles and was used as the adsorbent in the preparation of microcolumn. Silver ions were deposited by processing a standard or sample solution of analyte in the $\mathrm{pH}$ range of 3-9 through the microcolumn. Injection of $250 \mu \mathrm{L}$ of thiourea $\left(0.4 \mathrm{~mol} \mathrm{~L}^{-1}, \mathrm{pH}=5.0\right)$ served to elute the retained species to the FAAS. The capacity of the adsorbent under working conditions was found to be $7.2 \mathrm{mg}$ of silver per gram of adsorbent. Processing a water sample volume of $30 \mathrm{~mL}$ resulted in an enrichment factor of 116 . The method was successfully applied to the determination of silver in different natural waters and a certified reference material.

Keywords: silver determination, flow injection, flame atomic absorption spectrometry, water samples, modified bentonite, microcolumn.

\section{INTRODUCTION}

$\mathbf{S}$ ILVER is a rare but naturally occurring metal that is often found deposited as a mineral ore in association with other elements. Silver enters into the environment through anthropogenic activities such as those related to the electrical, chemical, and jewelry industries. ${ }^{[1-3]}$ The concentration of silver in rivers, lakes, and estuaries are about $0.01 \mu \mathrm{g} \mathrm{L}^{-1}$ for pristine waters in unpolluted areas and $0.01-0.10 \mu \mathrm{g} \mathrm{L}^{-1}$ in waters in urban and industrialized areas. ${ }^{[4]}$ Silver may pose a potential risk as a water pollutant because of the lack of recycling of mined silver. ${ }^{[5]}$ Thus, it is important to assess whether trace amounts of silver are present in water samples.

Flame atomic absorption spectrometry (FAAS) is commonly chosen technique for metal determination because of its advantages in terms of accuracy, precision, ease of operation and speed. ${ }^{[6]}$ However, due to FAAS's disadvantages of low sensitivity and matrix interferences, direct determination of trace levels of silver in environmental samples is not always possible. Thus, for the determination of silver present in water samples at microgram per liter concentration levels, a separation/preconcentration step is required. Among the different techniques used for preconcentration and determination of silver, [7-12] a combination of solid-phase extraction (SPE) and flow injection (FI) in on-line systems has attracted increasing attention because of its high precision, low consumption of samples and reagents, minimal waste production, and high sampling rate.[13-18] Choosing the proper adsorbent material for SPE is crucial. In the search for a new adsorbent, the main goals should be enhancement of selectivity, improvement of the capacity and thermal, chemical, and mechanical stability of the adsorbent. [19] 
Some bentonite (Bt) clays that are rich in montmorillonite (Mt) are soft. Mt is an extremely soft clay mineral that typically forms microscopic crystals. The primary layer of $\mathrm{Mt}$ is composed of two tetrahedral silica and an octahedral central alumina layers. Isomorphic substitution (for example, $\mathrm{Al}^{3+}$ instead of $\mathrm{Si}^{4+}$ in the tetrahedral layer and $\mathrm{Mg}^{2+}$ instead of $\mathrm{Al}^{3+}$ in the octahedral layer) creates a net negative charge that is delocalized on the clay mineral layers. These negative charges are neutralized by exchangeable cations in the interlayer such as $\mathrm{H}^{+}, \mathrm{Na}^{+}, \mathrm{K}^{+}, \mathrm{Mg}^{2+}$, and $\mathrm{Ca}^{2+}$. The cations are strongly hydrated in the presence of water giving a hydrophilic character to the clay mineral surface. Furthermore, as the clay and clay minerals have primary particles with at least one dimension in the nanometer scale, they can be regarded as nanomaterial of geological and pedological origin. ${ }^{[20,21]}$ Due to their highly specific surface area, high cationic exchange capacity (CEC), and high abundance and resulting low price, clay minerals can be used as effective, environmentally friendly adsorbents for metal ions. The adsorption capacity and character of the clay minerals have been modified by treatment with sulfuric acid[22] and humic acid, ${ }^{[23]}$ as well as by immobilization of anionic ${ }^{[24]}$ and cationic ${ }^{[25,26]}$ surfactants. Replacement of natural exchangeable cations with cationic surfactant makes the clay mineral surface more hydrophobic. ${ }^{[27]}$ Furthermore, the intercalation of cationic surfactant greatly increases the basal spacing of the layers. ${ }^{[28]}$ Zhang and Zhang [29] reported a direct modification of $\mathrm{Bt}$ with dithizone and used it for batch extraction of silver ions from water. To the best of our knowledge, bentonite modified with an organic ligand has not yet been employed as the adsorbent for the preparation of a microcolumn in an on-line FI-FAAS system.

In this study, the possibility of trapping an organic ligand on surfactant-modified Bt was considered, and dithizone was successfully trapped on the bentonite modified with cetyltrimethylammonium bromide (CTAB). The adsorbent was then used as the packing material for the microcolumn preconcentration of trace amounts of silver from water in the on-line FI-FAAS system.

\section{EXPERIMENTAL}

\section{Materials}

Bt was obtained from Kheyr Abad bentonite mine near the Kerman city, Iran. The chemical composition of used $\mathrm{Bt}$, determined by X-ray fluorescence (XRF) technique, is shown in Table 1. The certified reference material BCR288 (Lead with added impurities) was supplied by Institute for Reference Materials and Measurements (Geel, Belgium). All chemicals were of highest purity
Table 1. Chemical composition of bentonite determined by $\mathrm{X}$-ray fluorescence spectrometry

\begin{tabular}{lc}
\hline Chemical constituents & Mass fraction / \% \\
\hline $\mathrm{SiO}_{2}$ & 67.3 \\
$\mathrm{Al}_{2} \mathrm{O}_{3}$ & 14.9 \\
$\mathrm{Fe}_{2} \mathrm{O}_{3}$ & 4.0 \\
$\mathrm{MgO}$ & 2.8 \\
$\mathrm{CaO}$ & 1.7 \\
$\mathrm{Na}_{2} \mathrm{O}$ & 2.3 \\
$\mathrm{~K}_{2} \mathrm{O}$ & 0.4 \\
Loss on ignition & 6.0 \\
\hline
\end{tabular}

available from Merck (Darmstadt, Germany) and were used as received. Deionized water was used throughout the experiments.

\section{Apparatus}

An Analytik Jena novAA 300 (model 330, Germany) atomic absorption spectrometer equipped with a silver hollow cathode lamp and air acetylene flame was used for all absorption measurements. The hollow cathode lamp current was $4.0 \mathrm{~mA}$, the wavelength was set at $328.1 \mathrm{~nm}$ (the resonance line of silver) and the slit width was $1.2 \mathrm{~nm}$. The flow injection system used were as previously described, ${ }^{[6,17]}$ and consisted of a peristaltic pump (Ismatic, MS- REGLO/8-100, Switzerland), a rotary injection valve (Rheodyne, CA, USA), and a microcolumn (PTFE tube $3 \mathrm{~cm}$ $\times 4 \mathrm{~mm}$ id) of dithizone immobilized on surfactant-coated $B t$. The schematic diagram of flow injection system used is provided in Figure 1.

The X-ray diffraction (XRD) analysis was performed on a Bruker AXS D8 Advance diffractometer using CuKa radiation source generated at $40 \mathrm{KV}$ and $30 \mathrm{~mA}$. The data were collected at room temperature $\left(25^{\circ} \mathrm{C}\right)$ over the $2 \theta$ range of $2-90^{\circ}$. The XRF analysis was performed on the ARL ADVANT' $X$ spectrometer manufactured by Thermo Fisher Scientific Inc. The Fourier Transform Infrared (FT-IR) spectra were recorded on a Bruker FT-IR Equinax-55 spectrometer (Bruker $\mathrm{Co}$.) with the $\mathrm{KBr}$ pellets.

\section{Preparation of Standard Solutions}

The stock solution of silver ( $\left.1000 \mu \mathrm{g} \mathrm{mL}^{-1}\right)$ was prepared by dissolving an appropriate mass of $\mathrm{AgNO}_{3}$ (Merck) in water and diluting to the mark in a $100 \mathrm{~mL}$ volumetric flask. Working solutions were prepared daily from the stock solution by appropriate dilution with deionized water. The stock solution was wrapped in aluminum foil and kept in cold, dark, and dry place. 
a) $\quad \mathrm{P}$

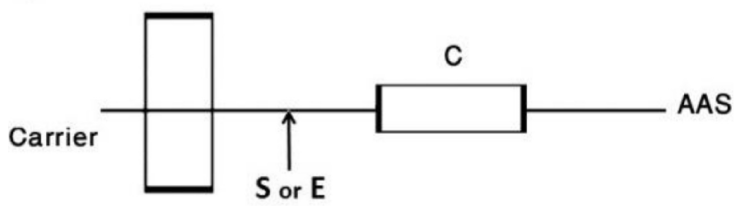

C

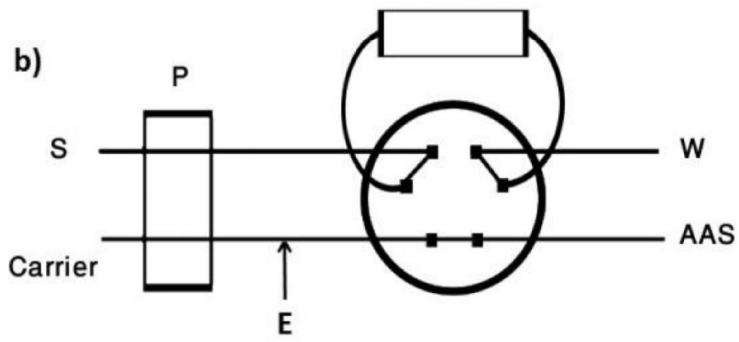

C

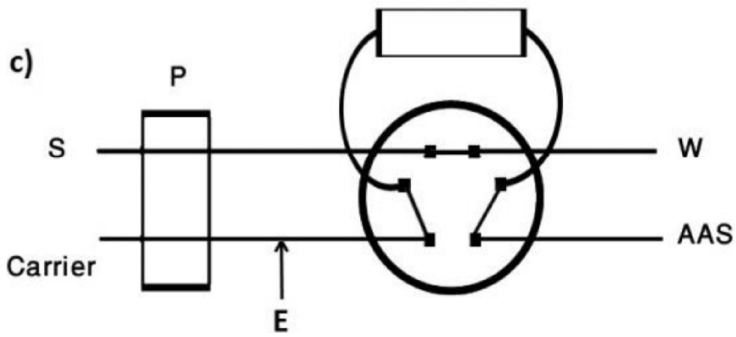

Figure 1. Schematic diagram of the flow injection system: a) single line $\mathrm{Fl}$ system, b) two line $\mathrm{FI}$ manifold (loading), c) two line FI manifold (elution). S - sample, E - eluent, W - waste, P - pump; Carrier: water; Eluent: thiourea $(250 \mu \mathrm{L}, 0.4 \mathrm{~mol}$ $\mathrm{L}^{-1}, \mathrm{pH}=5$ ); Sample $\mathrm{pH}: \approx 3$.

\section{Preparation of the Adsorbent}

Fifty milliliters of an aqueous solution containing $100 \mathrm{mg}$ CTAB was added to $1.5 \mathrm{~g}$ of $\mathrm{Bt}$ and the mixture was stirred with a magnetic stirrer for 5 minutes. Then, $0.2 \mathrm{~g}$ of dithizone dissolved in $10 \mathrm{~mL}$ of $20 \%$ ammonia solution was slowly added and the mixture was stirred for 15 minutes. This mixture was then filtered through a Millipore filter, using a vacuum pump and the solid product was washed several times with deionized water. Finally, it was air-dried and kept in a closed bottle before use. The color of the prepared adsorbent was dark brown. The adsorbent was stable for several weeks and it was used for preparation of the microcolumn.

\section{Preparation of the Microcolumn}

The microcolumn was prepared by filling a PTFE (Teflon) tube $(3 \mathrm{~cm}$ in length, internal diameter of $4 \mathrm{~mm}$ ) with dithizone immobilized on surfactant-coated Bt $(\approx 150 \mathrm{mg})$. The end of the tube was fitted with glass wool to keep the adsorbent in the tube.

\section{Procedure}

The flow injection manifolds were connected directly to the nebulizer inlet tubing. A single-line (Figure 1a) system was used to study the analyte breakthrough and in the initial method development experiments. The two-line FI manifold (Figure $1 \mathrm{~b}$ and $1 \mathrm{c}$ ) was used to process the real samples and to obtain the performance data. The carrier was water and the eluent was an aqueous solution of thiourea $\left(0.4 \mathrm{~mol} \mathrm{~L}^{-1}, \mathrm{pH}=5\right)$. The microcolumn was located in the sample loop of the injection valve so that the sampling could be performed "off-line" to prevent the matrix constituents from entering the FAAS. At the end of the sampling, the valve was switched to "on-line" and the analyte was eluted by injection of the eluent using a second valve.

The $\mathrm{pH}$ of the silver standard and sample solutions was adjusted to 3.0 by the addition of diluted nitric acid. With reference to the $\mathrm{Fl}$ manifold, standard or sample solutions were passed through the microcolumn $(30 \mathrm{~mL}$ at a flow rate of $3 \mathrm{~mL} \mathrm{~min}^{-1}$ ) to retain the analyte. The retained silver was then eluted by injection of $250 \mu \mathrm{L}$ of eluent solution and transported to the flame atomic absorption spectrometer for quantification. In the two-line FI system (Figure 1c), prior to the injection of eluent, the injection valve was switched to bring the microcolumn on-line. The transient signals were monitored for quantitative analysis.

\section{Analysis of Water Samples}

Water samples were filtered through the $0.45 \mu \mathrm{m}$ Millipore filter. The $\mathrm{pH}$ of a $30 \mathrm{~mL}$ water sample was adjusted to $\sim 3$ and the analyte was determined according to the described procedure.

\section{Preparation of Certified Reference Material BCR-288 for Analysis of Silver}

An exact amount $0.0492 \mathrm{~g}$ of the certified reference material was dissolved in $10 \mathrm{~mL}$ of concentrated nitric acid. The solution was heated to near dryness, and the procedure was repeated several times until the sample was completely digested. Then, $25 \mathrm{~mL}$ of water was added, the solution was filtered, diluted to $500 \mathrm{~mL}$ in a volumetric flask, and triplicate $30 \mathrm{~mL}$ aliquots were treated according to the developed procedure.

\section{RESULTS AND DISCUSSION}

The clay mineral was dried at $110{ }^{\circ} \mathrm{C}$ in an air oven for 12 hours and its chemical composition was determined by XRF technique (Table 1). The results indicated the presence of high amount of Mt. The cation exchange capacity of the Bt determined by ethylenediamine method [30] was 0.80 meq $\mathrm{g}^{-1}$ and by methylene blue method ${ }^{[31]} 0.72$ meq $^{-1}$. Its swelling index was found to be $24 \mathrm{~mL} / 2 \mathrm{~g}$. The basal spacing 


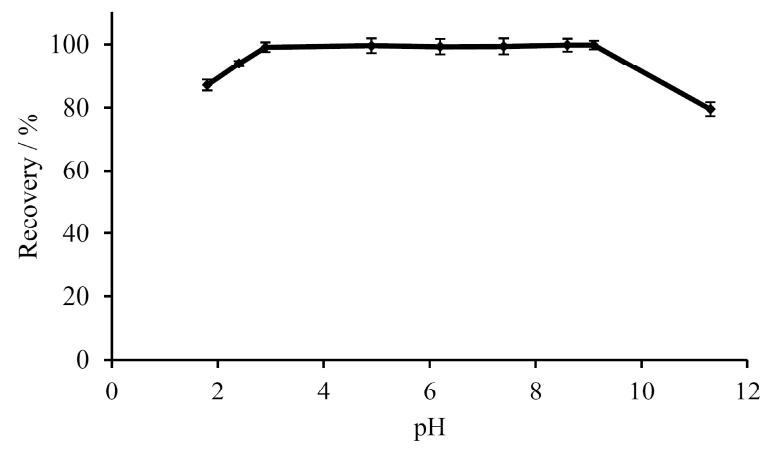

Figure 2. Effect of the sample $\mathrm{pH}$ on the recovery of silver from the adsorbent. Sample volume: $30 \mathrm{~mL}$; Mass concentration of silver: $25 \mu \mathrm{g} \mathrm{L}-1$; Sample flow rate: $2 \mathrm{~mL}$ $\mathrm{min}^{-1}$; Eluent flow rate: $2 \mathrm{~mL} \mathrm{~min}{ }^{-1}$; Eluent: thiourea (300 $\mu \mathrm{L}, 0.4 \mathrm{~mol} \mathrm{~L}^{-1}, \mathrm{pH}=5$ ).

d001-value calculated from XRD pattern of clay mineral was found to be $11.20 \AA$ before saturated with ethylene glycol and $16.00 \AA$ after saturated with ethylene glycol.[32]

The preliminary experiments revealed that when dithizone was added to a solution containing CTABmodified $\mathrm{Bt}$, it was uniformly trapped on the hemimicelles or admicelles formed by the CTAB in a manner similar to clay or clay mineral modified with surfactant. ${ }^{[33,34]}$ The color of the Bt was changed from gray to dark brown. The resulting adsorbent was further characterized by FT-IR spectroscopy. The IR bands characteristic for immobilized dithizone were at $2360.28 \mathrm{~cm}^{-1}$ (C=S stretching) and $1636.78 \mathrm{~cm}^{-1}$ ( $\mathrm{C}=\mathrm{C}$ of aromatic rings) which further supported the loading of dithizone on CTAB-modified Bt. (The characteristic dithizone bands were at about 3391, 2360, 1624 and $1500 \mathrm{~cm}^{-1}$ ).

\section{Optimization of Experimental Conditions for Microcolulmn Preconcentration of Silver Ions}

In order to establish the best experimental conditions for adsorption and desorption of silver ions, experimental variables affecting the immobilized dithizone microcolumn preconcentration system were optimized using the univariable method. In the optimization study $30 \mathrm{~mL}$ of a 20 $\mu \mathrm{g} \mathrm{L}^{-1} \mathrm{Ag}^{+}$aqueous solution was processed and three independent experiments were carried out for each measurement.

\section{Effect of Sample pH}

The $\mathrm{pH}$ of sample solution was an important factor affecting the retention of analyte on the microcolumn. The influence of the sample $\mathrm{pH}$ on the recovery of silver was investigated in the $\mathrm{pH}$ range of 2-11 (Figure 2). The $\mathrm{pH}$ was adjusted by either diluted nitric acid or sodium hydroxide.
Table 2. Effect of nature of eluents on the recovery of silver adsorbed on immobilized dithizone microcolumn

\begin{tabular}{lc}
\hline Eluent & Recovery of Silver ${ }^{(a)} / \%$ \\
\hline Nitric acid $\left(2 \mathrm{~mol} \mathrm{~L}^{-1}\right)$ & $84.3 \pm 2.7$ \\
Sulfuric acid $\left(2 \mathrm{~mol} \mathrm{~L}^{-1}\right)$ & $81.5 \pm 2.5$ \\
EDTA $\left(0.1 \mathrm{~mol} \mathrm{~L}^{-1}\right)$ & $75.9 \pm 0.9$ \\
Methanol & $11.2 \pm 0.8$ \\
Ethanol & $15.2 \pm 1.5$ \\
Oxalic acid $\left(0.25 \mathrm{~mol} \mathrm{~L}^{-1}\right)$ & $69.8 \pm 2.2$ \\
Sodium oxalate $\left(0.1 \mathrm{~mol} \mathrm{~L}^{-1}\right)$ & $55.7 \pm 0.9$ \\
Sodium fluoride $\left(0.25 \mathrm{~mol} \mathrm{~L}^{-1}\right)$ & $37.4 \pm 1.7$ \\
Thiourea $\left(0.2 \mathrm{~mol} \mathrm{~L}^{-1}, \mathrm{pH}^{-1}\right)$ & $92.1 \pm 1.8$ \\
Ammonium nitrate $\left(0.25 \mathrm{~mol} \mathrm{~L}^{-1}\right)$ & $19.5 \pm 1.6$ \\
\hline (a) Mean value \pm standard deviation $(n=3)$ &
\end{tabular}

As demonstrated in Figure 2, the analyte retention was not dependent on sample $\mathrm{pH}$ in the range of 3-9. The extreme decrease in adsorption of silver at $\mathrm{pH}$ greater than 9 was due to the formation of silver hydroxide which precipitates in the microcolumn, while the decrease in the retention of silver at $\mathrm{pH}$ less than 3 was due to the protonation of $\mathrm{Bt}$ which resulted in the desorption of CTAB. However, in neutral and basic solutions dithizone forms complexes with various ions, but in acidic media it forms complexes only with certain metals, namely, $\mathrm{Pt}, \mathrm{Pd}, \mathrm{Cu}, \mathrm{Hg}$, and $\mathrm{Ag}$. Thus, in order to achieve the maximum efficiency as well as selectivity for silver sorption, a $\mathrm{pH}$ of $\approx 3$ was selected for subsequent studies.

\section{Effect of Nature, Concentration and Volume of Eluent}

The ideal eluent should elute the adsorbed metal ions without any effect on the sorbent. To choose the best eluent, some basic factors such as affinity of eluent for analyte, stability of sorbent and the recovery of silver ions were considered. Desorption of silver from the immobilized dithizone microcolumn was investigated by eluting the adsorbent with $300 \mu \mathrm{L}$ of 10 different eluents (Table 2). The use of highly acidic eluents such as $2 \mathrm{~mol} \mathrm{~L}^{-1}$ nitric and sulfuric acid can cause protonation of bentonite and consequently desorption of CTAB. The best recovery was achieved with thiourea due to the formation of complex with silver ion. The concentration and $\mathrm{pH}$ (Figure 3) of thiourea were optimized by performing desorption experiments at eluent concentrations and $\mathrm{pH}$ values ranging from 0.1 to $1.2 \mathrm{~mol} \mathrm{~L}^{-1}$ and from 1 to 12 , 


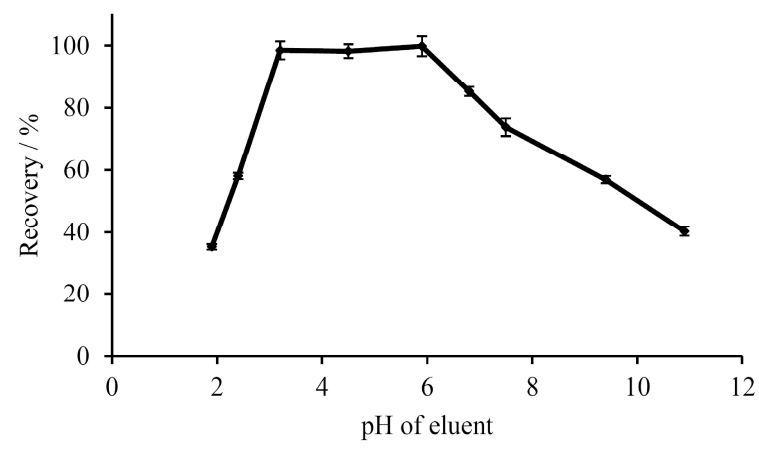

Figure 3. Effect of the $\mathrm{pH}$ of thiourea solution on the recovery of silver from the adsorbent. Sample volume: 30 $\mathrm{mL}$; Mass concentration of silver: $25 \mu \mathrm{g} \mathrm{L}^{-1}$; Sample pH: 3.0; Sample flow rate: $3 \mathrm{~mL} \mathrm{~min}{ }^{-1}$; Eluent flow rate: $2 \mathrm{~mL} \mathrm{~min}^{-1}$; Eluent: thiourea $\left(300 \mu \mathrm{L}, 0.4 \mathrm{~mol} \mathrm{~L}^{-1}\right)$

respectively. As it is demonstrated, the recovery of silver reaches its highest value when the eluent $\mathrm{pH}$ is in the range of 3-6. In extremely acidic conditions, the thiourea is protonated and its capability for desorption of silver from the sorbent is decreased, while in highly basic media precipitation of silver as silver hydroxide can occur. A 0.4 mol L-1 thiourea of $\mathrm{pH}=5$ turned out to be the best eluent for desorption of silver ions and it was selected for further experiments.

The volume of eluent is an important factor which affects the preconcentration capability of the extraction system. A decrease in the eluent volume will increase the preconcentration factor, but it might reduce the recovery of the analyte from the adsorbent. For this purpose, the effect of different volumes of thiourea $\left(0.4 \mathrm{~mol} \mathrm{~L}^{-1}, \mathrm{pH}=5\right)$, on desorption of silver ions from the adsorbent was examined (Figure 4) and it was found that $250 \mu \mathrm{L}$ of the eluent was sufficient for the quantitative recovery of the analyte.

\section{Effect of Flow Rate on Adsorption and Desorption of Analyte}

Sample flow rate is another important factor which affects the speed of analysis. It was necessary to select a sample flow rate that guarantees the achievement of the analyte equilibrium between the sample and the adsorbent. The effect of sample flow rate on the analyte adsorption on the microcolumn was investigated by varying the flow rate of aqueous sample from 1 to $5 \mathrm{~mL} \mathrm{~min} \mathrm{~m}^{-1}$. It was found that up to a flow rate of $3 \mathrm{~mL} \mathrm{~min}{ }^{-1}$ the uptake of silver was constant and then decreased with further increasing the flow rate. Thus, a sample flow rate of $3 \mathrm{~mL} \mathrm{~min}^{-1}$ was selected as the optimal. The effect of eluent flow rate on the recovery of silver ions was also investigated. It was found that with $250 \mu \mathrm{L}$ of $0.4 \mathrm{~mol} \mathrm{~L}^{-1}$ thiourea $(\mathrm{pH}=5)$ at a

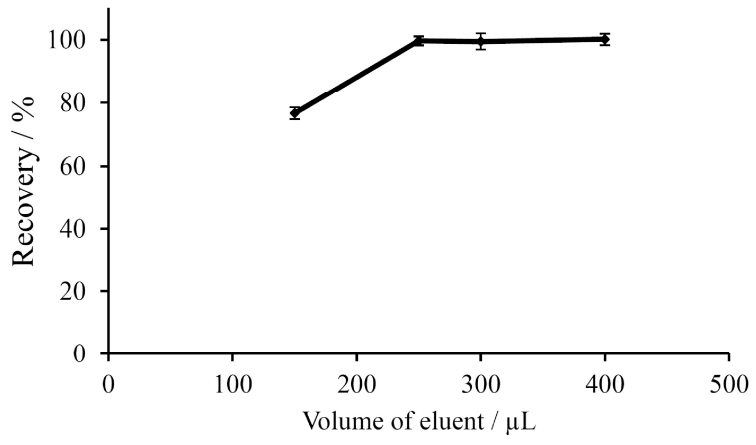

Figure 4. Effect of the volume of thiourea on the recovery of silver from the adsorbent. Sample volume: $30 \mathrm{~mL}$; Mass concentration of silver: $20 \mu \mathrm{g} \mathrm{L} \mathrm{L}^{-1}$; Sample $\mathrm{pH}$ : 3.0; Sample flow rate: $2 \mathrm{~mL} \mathrm{~min}-1$; Eluent flow rate: $2 \mathrm{~mL} \mathrm{~min}{ }^{-1}$; Eluent: thiourea $\left(0.4 \mathrm{~mol} \mathrm{~L}^{-1}, \mathrm{pH}=5\right)$.

flow rate of $2.0 \mathrm{~mL} \mathrm{~min}{ }^{-1}$, the quantitative elution of $\mathrm{Ag}^{+}$ ions from the microcolumn can be achieved in about $10 \mathrm{~s}$.

\section{Interferences Study}

The efficiency of immobilized dithizone microcolumn for preconcentration of silver ions (sample volume $30 \mathrm{~mL}, \mathrm{Ag}^{+}$ concentration $20 \mu \mathrm{g} \mathrm{L}^{-1}$ ) was examined in the presence of various foreign ions. The results are shown in Table 3. A relative error of less than $5 \%$ was considered to be within the range of experimental error. As the results indicated, the tolerance limit for some ions forming a more stable complex with dithizone $\left(\mathrm{Zn}^{2+}, \mathrm{Pb}^{2+}, \mathrm{Hg}^{2+}, \mathrm{Cu}^{2+}\right)$ was lower. However, at the given foreign ion to $\mathrm{Ag}^{+}$mole ratio, they have no significant effect on the determination of trace amounts of silver. Thus, the selectivity of the method is mainly due to the high affinity of dithizone for silver ion in acidic media. The method has good selectivity for silver species relative to the matrix ions and the high concentration of foreign ions has minimal effect on the determination of the analyte.

\section{Analytical Performance}

The preconcentration capability of the microcolumn extraction system was tested by processing $0.6 \mu \mathrm{g}$ of silver dissolved in different volumes of water $(5-100 \mathrm{~mL})$ according to the optimized procedure. The results showed that up to a sample volume of $90 \mathrm{~mL}$, the extraction was quantitative. Thus the breakthrough volume for silver ions is $90 \mathrm{~mL}$. The proposed method showed good linearity for the preconcentration of silver ions from $30 \mathrm{~mL}$ of standard solution over the concentration range of 0.4 to $35.0 \mu \mathrm{g} \mathrm{L}^{-1}$. The equation for the calibration line was $A=0.007 C-0.001$ (where $A$ is the absorbance and $C$ is the silver concentration in $\mu \mathrm{g} \mathrm{L}^{-1}$ ) with a correlation coefficient of 0.999. Based on the ratio of slopes of calibration lines obtained by analysis 
Table 3. The influence of some matrix ions on the recoveries of silver extracted from water by SPE system

\begin{tabular}{|c|c|c|c|c|c|}
\hline Foreign ion & $\begin{array}{c}\text { Molar ratio } \\
\left(\text { ion } / \mathrm{Ag}^{+}\right)\end{array}$ & Recovery $^{(a)} / \%$ & Foreign ion & Molar ratio (ion $/ \mathrm{Ag}^{+}$) & Recovery $^{(a)} / \%$ \\
\hline $\mathrm{Ni}^{2+}$ & 1000 & $98.0 \pm 1.5$ & $\mathrm{Cr}^{2+}$ & 1000 & $99.5 \pm 2.0$ \\
\hline $\mathrm{Ca}^{2+}$ & 1000 & $95.4 \pm 0.9$ & $\mathrm{Sr}^{2+}$ & 1000 & $96.9 \pm 0.9$ \\
\hline $\mathrm{Mg}^{2+}$ & 1000 & $98.6 \pm 2.2$ & $\mathrm{Ca}^{2+}$ & 1000 & $102.8 \pm 0.9$ \\
\hline $\mathrm{Mn}^{2+}$ & 1000 & $102.7 \pm 1.7$ & $\mathrm{Ba}^{2+}$ & 1000 & $97.9 \pm 1.9$ \\
\hline $\mathrm{Cd}^{2+}$ & 1000 & $100.8 \pm 1.2$ & $\mathrm{~Pb}^{2+}$ & 750 & $98.0 \pm 1.5$ \\
\hline $\mathrm{Zn}^{2+}$ & 500 & $97.5 \pm 1.9$ & $\mathrm{Al}^{3+}$ & 1000 & $99.7 \pm 2.1$ \\
\hline $\mathrm{Co}^{2+}$ & 1000 & $98.2 \pm 0.8$ & $\mathrm{Hg}^{2+}$ & 250 & $102.3 \pm 1.9$ \\
\hline $\mathrm{Bi}^{3+}$ & 1000 & $97.6 \pm 2.5$ & $\mathrm{Cu}^{2+}$ & 100 & $97.5 \pm 1.5$ \\
\hline $\mathrm{Fe}^{3+}$ & 1000 & $104.1 \pm 1.6$ & $\mathrm{SO}_{4}{ }^{2-}$ & 1000 & $99.0 \pm 0.9$ \\
\hline $\mathrm{Sb}^{3+}$ & 1000 & $98.3 \pm 1.3$ & & & \\
\hline
\end{tabular}

a) Mean value \pm standard deviation $(n=3)$

of aqueous silver solutions prepared with and without microcolumn preconcentration, for a sample volume of 30 $\mathrm{mL}$, an enrichment factor of 116 was calculated. The enrichment factor was close to the preconcentration factor $(30 / 0.25=120)$, indicating that the uptake and elution of the analyte was quantitative. Furthermore, as the recovery of analyte was quantitative up to a sample volume of 90 $\mathrm{mL}$, processing sample volumes greater than $30 \mathrm{~mL}$ would result in the improved sensitivity of the method.

The capacity of the adsorbent was determined using the batch method. The experiment was carried out via the addition of $0.25 \mathrm{~g}(250 \mathrm{mg})$ of adsorbent to $50 \mathrm{~mL}$ of an aqueous solution $(\mathrm{pH}=3$ ) containing $10 \mathrm{mg}$ of silver ions. The mixture was shaken with a mechanical shaker for 45 min and then filtered through a sintered glass funnel. The amount of silver left in the solution was determined by FAAS. The maximum mass of silver retained on the adsorbent was found to be $7.2 \mathrm{mg}$ of $\mathrm{Ag}^{+}$per gram of adsorbent. Zhang and Zhang ${ }^{[29]}$ reported a direct modification of Bt with dithizone and a sorbent capacity for silver ions of $19.7 \mathrm{mg} \mathrm{g}^{-1}$. This difference in capacities can be related to the natural source of bentonite as well as the mechanism of immobilization of dithizone. The important benefits of the sorbent prepared in this work are the easy preparation and reusability.

At the 95\% confidence level, the relative standard deviation (RSD) of seven replicate analyses of $30 \mathrm{~mL}$ samples with a $20.0 \mu \mathrm{g} \mathrm{L}^{-1}$ concentration of silver was $2.1 \%$. The limits of detection and quantification were calculated as 3 and 10 standard deviations of the blank signal. Based on processing of a water sample volume of $30 \mathrm{~mL}$, the silver detection and quantification limits were 0.08 and $0.25 \mu \mathrm{g}$ $\mathrm{L}^{-1}$, respectively.

\section{Applications}

The developed method was applied to the determination of silver ions in tap water, well water, spring water, rain, and river water. Reliability of the method was tested by spiking experiments and comparing the results with the data obtained by electrothermal atomic absorption spectrometry (ETAAS). As shown in Table 4, the recoveries of silver from spiked water samples were quantitative. At 95\% confidence level there was a satisfactory agreement between the results of the newly developed method and data obtained by ETAAS, confirming that the FI-AAS procedure was suitable for analysis of silver in sample types examined (Table 4). Furthermore, the FI-AAS procedure was applied to the determination of silver in certified reference material BCR-288 (Lead with added impurities) containing $30.5 \pm 0.5 \mu \mathrm{g} \mathrm{g}^{-1} \mathrm{Ag}, 55.7 \pm 1.6 \mu \mathrm{g} \mathrm{g}-1 \mathrm{As}, 215.8 \pm$ $2.4 \mu \mathrm{g} \mathrm{g}^{-1} \mathrm{Bi}, 33.3 \pm 0.9 \mu \mathrm{g} \mathrm{g}^{-1} \mathrm{Cd}, 19.3 \pm 0.4 \mu \mathrm{g} \mathrm{g}{ }^{-1} \mathrm{Cu}, 4.57$ $\pm 0.11 \mu \mathrm{g} \mathrm{g}^{-1} \mathrm{Ni}, 32.5 \pm 0.9 \mu \mathrm{g} \mathrm{g}^{-1} \mathrm{Sb}, 0.2 \mu \mathrm{g} \mathrm{g}^{-1} \mathrm{Se}, 30.6 \pm$ $1.5 \mu \mathrm{g} \mathrm{g}^{-1} \mathrm{Sn}, 32.8 \pm 1.3 \mu \mathrm{g} \mathrm{g}^{-1} \mathrm{Te}, 2.3 \pm 0.1 \mu \mathrm{g} \mathrm{g}^{-1} \mathrm{Tl}$, and 8.2 $\pm 0.4 \mu \mathrm{g} \mathrm{g}^{-1} \mathrm{Zn}$. The accuracy of the method was assessed by comparing the obtained data with the accepted value. The mass fraction of silver in the BCR-288 sample was found to be $29.1 \pm 0.8 \mu \mathrm{g} \mathrm{g}^{-1}$ which was in good agreement with the accepted value of $30.5 \pm 0.5 \mu \mathrm{g} \mathrm{g}^{-1}$. Thus, the method was suitable for analysis of silver in this type of sample. In other words, the procedure is reliable for analysis of a wide range of samples.

\section{Comparison of the Developed Method with other SPE-FAAS Methods}

Preconcentration and determination of silver by the developed method was compared with other SPE methods reported for the separation and preconcentration of silver 
Table 4. Mass concentrations of silver measured in different water samples

\begin{tabular}{|c|c|c|c|c|}
\hline \multirow{2}{*}{ Water samples } & \multicolumn{2}{|c|}{ Silver / $\mu \mathrm{g} \mathrm{L}{ }^{-1}$} & \multirow{2}{*}{ Recovery / \% } & \multirow{2}{*}{$\begin{array}{l}\text { ETAAS analysis }^{(\mathrm{a})} \\
\text { Silver / } \mu \mathrm{g} \mathrm{L}^{-1}\end{array}$} \\
\hline & Added & Found ${ }^{(a)}$ & & \\
\hline \multirow{2}{*}{ Tap water } & 0 & $1.8 \pm 0.1$ & --- & $1.6 \pm 0.1$ \\
\hline & 10 & $11.9 \pm 0.5$ & 101.0 & --- \\
\hline \multirow{2}{*}{ Well water } & 0 & $2.1 \pm 0.1$ & --- & $2.5 \pm 0.2$ \\
\hline & 10 & $12.5 \pm 0.2$ & 104.0 & --- \\
\hline \multirow{2}{*}{ Spring water } & 0 & $N D^{(b)}$ & --- & --- \\
\hline & 10 & $9.9 \pm 0.2$ & 99.0 & --- \\
\hline \multirow{2}{*}{ Rain water } & 0 & $N D^{(b)}$ & --- & --- \\
\hline & 10 & $10.2 \pm 0.3$ & 102.0 & --- \\
\hline \multirow{2}{*}{ River water(c) } & 0 & $5.3 \pm 0.1$ & --- & $5.6 \pm 0.2$ \\
\hline & 10 & $15.1 \pm 0.4$ & 98.0 & --- \\
\hline
\end{tabular}

(a) Average of three independent determinations \pm standard deviation

(b) ND: not detected

(c) Zayandeh rood river/Esfahan-Iran

prior to its determination by FAAS (Table 5). Thus, the silver enrichment factor achieved by processing the $30 \mathrm{~mL}$ sample volumes was higher or comparable with values achieved in other studies. With the exception of the sorbent reported by Zhang and Zhang, [29] the capacity of the sorbent prepared in this work is higher than capacities of all other sorbents listed in Table 5. Furthermore, the detection limit of silver ions is lower than values achieved by most of the other methods. The lower detection limits reported by Rofouei et al. ${ }^{[35]}$ and Zhang and Zhang, ${ }^{[29]}$ were based on processing a sample volume of $1800 \mathrm{~mL}$ and 500 $\mathrm{mL}$, respectively, whereas the sample volume in the present method was $30 \mathrm{~mL}$. Nevertheless, the developed
SPE is an on-line preconcentration system, whereas most of the reported SPE procedures for preconcentration of silver are off-line.

\section{CONCLUSIONS}

A new type of adsorbent based on organically modified Bt was prepared, and a simple FI-FAAS method was developed to determine trace amounts of silver in several categories of natural water. The adsorbent showed a high affinity for adsorption of silver in the presence of different matrix ions. The adsorbent is environmentally friendly, easily prepared, and it can be used in at least 10 adsorption/desorption

Table 5. Characteristic performance of different SPE methods developed for silver determination by FAAS

\begin{tabular}{|c|c|c|c|c|c|c|c|}
\hline Sample type & Sorbent & $\begin{array}{c}\text { Sample volume } \\
\qquad / \mathrm{mL}\end{array}$ & $\begin{array}{l}\text { Enrichment } \\
\text { factor }\end{array}$ & $\begin{array}{c}\text { Capacity / } \\
\mathrm{mg} \mathrm{g}^{-1}\end{array}$ & RSD / \% & $\begin{array}{c}\text { Detection } \\
\text { limit / } \mu g \mathrm{~L}^{-1}\end{array}$ & Ref. \\
\hline $\begin{array}{l}\text { Natural waters, } \\
\text { radiology film }\end{array}$ & $\begin{array}{l}\text { Modified surfactant- } \\
\text { coated alumina }\end{array}$ & 20 & 125 & 0.514 & 4.0 & 1.7 & {$[6]$} \\
\hline River water & $\begin{array}{l}\text { Modified surfactant- } \\
\text { coated alumina }\end{array}$ & 5 & --- & --- & 3.2 & --- & {$[36]$} \\
\hline $\begin{array}{c}\text { Mineral and tap } \\
\text { water }\end{array}$ & $\begin{array}{c}\text { Moringa oleifera } \\
\text { seeds }\end{array}$ & 14 & 35 & --- & 3.8 & 0.22 & [37] \\
\hline $\begin{array}{c}\text { Spring and tap } \\
\text { water }\end{array}$ & Modified silica gel & 130 & 130 & 0.38 & 3.03 & --- & {$[38]$} \\
\hline Water & $\begin{array}{l}\text { Benzil derivative of } \\
\text { polyacrylohydrazide }\end{array}$ & 1000 & 100 & --- & 5.3 & --- & [39] \\
\hline Water samples & $\begin{array}{l}\text { Modified octadecyl } \\
\text { silica membrane disk }\end{array}$ & 1800 & 360 & 1.07 & --- & 0.006 & {$[34]$} \\
\hline Water samples & Modified bentonite & 500 & 100 & 19.7 & --- & 0.02 & {$[35]$} \\
\hline Natural waters & Modified bentonite & 30 & 116 & 7.2 & 2.1 & 0.08 & This work \\
\hline
\end{tabular}


cycles without significant adsorption property loss. Furthermore, the selectivity, detection limits and precision of the developed method indicate its suitability for the measurement and monitoring of silver in different natural waters. The main benefits of the new method are the use of natural adsorbent, enhancement of FAAS sensitivity, elimination of interfering matrix constituents, speed of analysis, and simplicity.

\section{REFERENCES}

[1] F. Sabermahani, M. A. Taher, H. Bahrami, Z. Hassani, Intern. J. Environ. Anal. Chem. 2013, 93, 265.

[2] N. Goudarzi, M. Sarikhan Kheljani, M. Arab Chamjangali, Croat. Chem. Acta 2014, 87(3), 241.

[3] I. M. Kolthoff and P. J. Elwing, (Eds.), Treatise on Analytical Chemistry, Part 11, Vol. 4, Interscience, New York, 1966.

[4] ATSDR (Agency for Toxic Substances and Disease Registry). Toxicological Profile for Silver. Prepared by Clement International Corporation, under Contract 205-88-0608. U.S. Public Health Service. ATSDR/TP90-24 (1990).

[5] H. J. M. Bowen, Trace Element Biochemistry, Academic Press, London, 1966.

[6] S. Dadfarnia, A. M. Haji Shabani, M. Gohari, Talanta 2004, 64, 682.

[7] M. C. Bruzzoniti, D. K. Kobylinska, M. Franko, C. Sarzanini, Anal. Chim. Acta 2010, 665, 69.

[8] S. Dadfarnia, A. M. Haji Shabani, Anal. Chim. Acta 2010, 658, 107.

[9] W. Guo, S. Hu, J. Zhang, H. Zhang, Sci. Total Environ. 2011, 409, 2981.

[10] A. M. Haji Shabani, S. Dadfarnia, A. A. Jafari, Z. Shahbazi, Can. J. Anal. Sci. Spectros. 2006, 51, 194.

[11] A. A. Hill, R. J. Lipert, M. D. Porter, Talanta 2010, 80, 1606.

[12] Z. Shahbazi, S. Dadfarnia, A. M. H. Shabani, A. A. Jafari, J. Anal. Chem. 2008, 63, 446.

[13] A. N. Anthemidis, G. Giakisikli, S. Xidia, M. Miro, Microchem. J. 2011, 98, 66.

[14] S. Dadfarnia, M. Talebi, A. M. Haji Shabani, Z. Amani Benia, Croat. Chem. Acta 2007, 80, 17.

[15] A. M. Haji Shabani, S. Dadfarnia, Z. Dehghani, Talanta 2009, 79, 1066.
[16] W. R. Melchert, B. F. Reis, F. R. P. Rocha, Anal. Chim. Acta 2012, 714, 8.

[17] F. Shakerian, S. Dadfarnia, A. M. Haji Shabani, M. Rohani, Talanta 2008, 77, 551.

[18] H. M. Yu, H. Song, M.L. Chen, Talanta 2011, 85, 625.

[19] F. Augusto, E. Carasek, R. G. C. Silva, S.R. Rivellino, A. D. Batista, E. Martendal, J. Chromatogr. A 2010, 1217, 2533.

[20] D. Afzali, A. Mostafavi, H. Beitollah, Microchim Acta 2010, 171, 97.

[21] G. Yuan, L. Wu, Sci. Tech. Adv. Materials 2007, 8, 60.

[22] C. O. Ijagbemi, M. H. Baek, D. S. Kim, J. Hazard. Mater. 2010, 174, 746.

[23] P. Wu, Q. Zhang, Y. Dai, N. Zhu, Z. Dang, P. Li, J. Wu, X. Wang, Geoderma 2011, 164, 215.

[24] S. H. Lin, R. S. Juang, J. Hazard. Mater. 2002, 92, 315.

[25] O. Bouras, J. C. Bollinger, M. Baudu, Appl. Clay Sci. 2010, 50, 58.

[26] L.G. Yan, J. Wang, H. Q. Yu, Q. Wei, B. Du, X.Q. Shan, Appl. Clay Sci. 2007, 37, 226.

[27] X. Feng, G. Hu, X. Meng, Y. Ding, S. Zhang and M. Yang, Appl. Clay Sci. 2009, 45, 239.

[28] H. He, Y. Ma, J. Zhu, P. Yuan, Y., Qing, Appl. Clay Sci. 2010, 48, 67.

[29] D. Zhang, Y. L. Zhang, Appl. Mech.Mater. 2011, 71-78, 3508.

[30] F. Bergaya, M. Vayer, Appl. Clay Sci. 1997, 12, 275.

[31] P. T. Hang, G. W. Brindley, Clays Clay Miner. 1970, 18, 203.

[32] R. Mosser-Ruck, K. Devineau, D. Charpentier, M. Cathelineau, Clays Clay Miner. 2005, 53, 631.

[33] N. L. Dias Filho, D. R. do Carmo, Talanta 2006, 68, 919.

[34] J. Zhu, T. Wang, R. Zhu, F. Ge, J. Wei, P. Yuan, H. He, Appl. Clay Sci. 2011, 51, 317.

[35] M. K. Rofouei, M. Payehghadr, M. Shamsipur, A. Ahmadalinezhad, J. Hazard. Mater. 2009, 168, 1184.

[36] G. Absalan, A. Aghaei Goudi, Sep. Purif. Technol. 2004, 38, 209.

[37] C. S. T. Araujo, V. N. Alves, H. C. Rezende, N. M. M. Coelho, Microchem. J. 2010, 96, 82.

[38] T. Madrakian, A. Afkhami, M. A. Zolfigol, M. Solgi, J. Hazard. Mater. 2006, 128, 67.

[39] G. Absalan, M. Akhond, A. Z. Ghanizadeh, Z. A. Abedi, B. Tamami, Sep. Purif. Technol. 2007, 56, 231. 